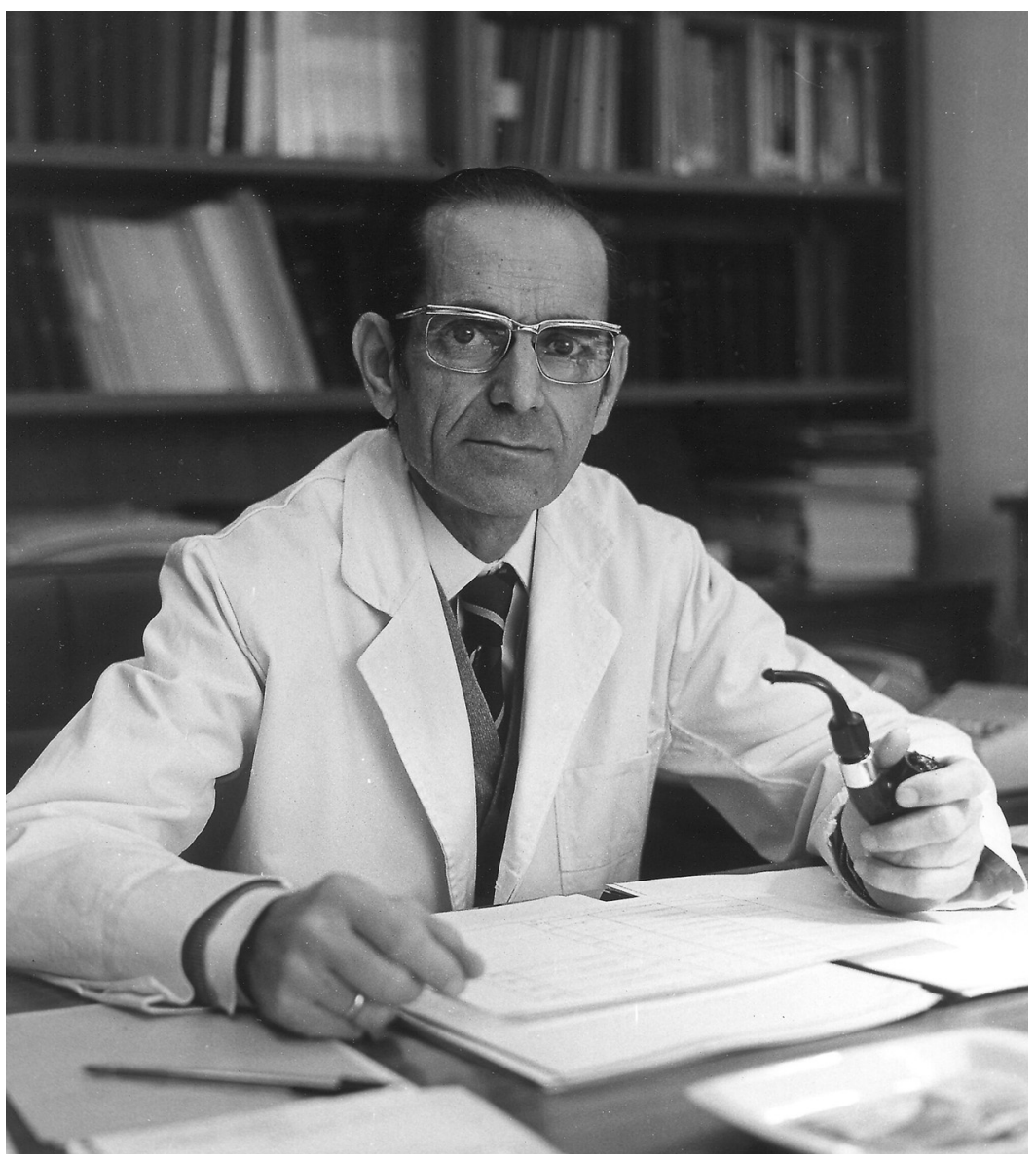

\title{
Buenaventura Andreu Morera 1920-2001
}

El Dr. Buenaventura Andreu Morera nació en Albalate de Cinca (Huesca) el 13 de mayo de 1920, hijo de D. Alfredo Andreu, farmacéutico de la misma localidad y de Doña María Morera. Los estudios de secundaria los realizó en los institutos de Huesca y Maragall de Barcelona. Aprovechando facilidades legales obtiene el título de magisterio en la Escuela Nacional de Lérida en 1940. Inmediatamente continúa sus estudios de Ciencias, Sección Naturales, en la Universidad de Barcelona, terminando en el curso 1945-46 en la Universidad de Madrid, aunque su licenciatura corresponde a la primera de ambas universidades.

Terminada su formación universitaria dirige sus investigaciones hacia las ciencias marinas con la ayuda del Centro de Investigaciones Zoológicas del Patronato Ramón y Cajal, en 1947. Desarrolla esta primera etapa en Santander. Un nuevo contrato con la compañía PYBSA le permite iniciar nuevos trabajos en Vinaroz. De aquí pasa, en 1949, a integrarse en el nuevo centro Sección de Biología Marina del Instituto de Biología Aplicada, actuando como coordinadordirector del centro instalado en Blanes. Su gran capacidad de trabajo le lleva a organizar el nuevo centro de Castellón (1949) y en 1951 el centro de Vigo. En 1965 es nombrado Director Adjunto del Instituto de Investigaciones Pesqueras con sede en Vigo, pasando a Director en 1967, cargo que ostenta hasta 1983. Continúa trabajando intensamente dedicando una atención especial a las publicaciones del Instituto hasta su jubilación en 1986. 
Su trayectoria como investigador viene marcada por dos líneas principales. La primera etapa está dedicada al estudio de diferentes problemas relacionados con la pesca y la biología de algunas especies explotadas, con una atención muy especial a la Sardina, a la que dedica 34 trabajos, destacando "Las branquiespinas en la caracterización de las poblaciones de Sardina pilchardus, Walb”. Tesis doctoral defendida en 1969. Pero pronto el Dr. Andreu se da cuenta de la importancia que tiene el cultivo de los moluscos y en especial del mejillón y de la ostra. El primer trabajo en esta nueva línea de investigación lo desarrolla en 1954, pero es a partir de las instalaciones que para el estudio experimental desarrolla en Villajuan (ría de Arosa) en 1965, cuando su gran capacidad investigadora adquiere su pleno desarrollo. Sus contactos con los centros más avanzados en este campo se multiplican y al mismo tiempo sus estudios y el prestigio alcanzado le invitan a asesorar y compartir numerosos trabajos de este tipo a nivel internacional. El número de publicaciones presentadas en este campo es de 37.

En una visión global humana de su actividad hay que destacar que, a pesar de su poco favorable estado de salud, no sólo no se siente limitado en sus posibilidades tanto en el campo de la investigación como en el de la gestión, sino que los que convivimos con él tuvimos la impresión de que esta situación fue para él importante estímulo que acrecentaba constantemente su capacidad de trabajo.

A modo de resumen de toda su actividad, hay que señalar que sus publicaciones fueron 96; su participación en congresos, 44, y conferencias, 20. Su extensa labor fue premiada con la concesión de la Encomienda de Alfonso X el Sabio. En 1999 fue nombrado Académico Correspondiente de la Real Academia de Ciencias y Artes de Barcelona y ese mismo año Hijo Predilecto de su villa natal, Albalate de Cinca.

Se jubiló en 1986 y la muerte le sobrevino en 2001 en su villa de Albalate de Cinca, a los 81 años, cuando se dedicaba con toda solicitud a su fuerte vida espiritual, aspecto que siempre fue primordial en su comportamiento.

Descanse en Paz.

Dr. Carles Bas Peired 